Original Research Paper

\title{
Immune Response, Detection of IgE and PGE2 during Vaginal Candidiasis in Mice
}

\author{
${ }^{1,2}$ Rosymar Coutinho Lucas, ${ }^{3}$ Rafael Taglialegna, ${ }^{4,5}$ Carolina Nunes França, \\ ${ }^{6}$ Fernando Segato, ${ }^{7}$ Rodrigo A. Cazzaniga, ${ }^{3}$ Carol K. Da Fonseca and ${ }^{2}$ Claudia M.L. Maffei \\ ${ }^{I}$ Department of Biochemistry, University of Sao Paulo, SP, Brazil \\ ${ }^{2}$ Department of Biology, University of Sao Paulo, SP, Brazil \\ ${ }^{3}$ Department of Cellular and Molecular Biology and Pathogenic Bioagents, University of Sao Paulo, SP, Brazil \\ ${ }^{4}$ Health Science Post Graduation, University of Santo Amaro, Brazil \\ ${ }^{5}$ Department of Medicine, Federal University of Sao Paulo, Brazil \\ ${ }^{6}$ Department of Biotechnology, Lorena School of Engineering, University of Sao Paulo, SP, Brazil \\ ${ }^{7}$ Department of Morphology, Federal University of Sergipe, SE, Brazil
}

Article history

Received: 05-12-2015

Revised: $12-07-2016$

Accepted: 13-07-2016

Corresponding Author: Rosymar Coutinho Lucas Department of Biochemistry, University of Sao Paulo, SP, Brazil

Fax: +55 1636023229

Email: rosymar_lucas@hotmail.com

\begin{abstract}
Vulvovaginal candidiasis is an opportunistic infection that affects most women in adult life, but the defense mechanism remains to be elucidated. Animals treated with estradiol were inoculated with Candida albicans having high virulence power. The experimental control consisted of animal groups treated with estradiol and animals without treatment that were inoculated with physiologic serum. The vaginal wall was collected, at different times. The material was destined to the counting of Colony Forming Units (CFU), detection of PGE2, $\operatorname{IgE}$ and histological staining (hematoxylin and eosin, silver and toluidine blue) for the study of the infected vaginal section. Experimental infection was predominant due to hyphae and pseudohyphae parasitism, involving the keratinized layer of the vaginal stratified squamous epithelium, without compromise submucosal or muscular layer. Furthermore, it was observed mast and polymorphonuclear cells on vaginal tissue in response to the infection. On the other hand, IgE and PGE2 participated in the response to experimental $C$. albicans vaginal infection. The raise in these mediators matches with the load fungal increase during the infection evolution and with the presence of mast cell. These results suggest a probable atopic component involved in the vaginal candidiasis pathogenesis.
\end{abstract}

Keywords: Immune Response, Vulvovaginal Candidiasis, Candida albicans, Mast Cell

\section{Introduction}

Candida albicans (C. albicans) is a pleomorphic fungus showing yeast, pseudohyphae and hyphae forms according to the environmental conditions (e.g., temperature and $\mathrm{pH}$ variation). This fungus is a diploid organism without meiosis division and its teleomorphic state has not been described yet (Bennett and Johnson, 2005). The host tissue invasion is mainly due to $C$. albicans plasticity and production of adhesion factors and extracellular proteolytic enzymes, factors which help its virulence power (McCullough et al., 1996). C. albicans is the most important causative agent in $85-90 \%$ of Vulvovaginal Candidiasis (VVC) symptomatic cases.
VVC is an opportunistic infection that affects $75 \%$ of women during their reproductive life and about $5 \%$ of them will develop Recurrent Vulvovaginal Candidiasis (RVVC) (Fidel et al., 1995; Carrara et al., 2010; Harriott et al., 2010; Yano et al., 2012). The mechanism of defense used by the host against this fungus is related to an activity of innate and adaptive immune response (Yano et al., 2012). However, the exact knowledge on how the putative immune system mechanisms of the female genital treatment react against this yeast is still unclear. Some evidences have shown the involvement of IgE and PGE2 production and also the histamine releasing by mast cells in the disease pathogenesis, but the cellular types involved in the immune response are 
not totally clear (Witikin et al., 1988; Noverr et al., 2001; 2002; Erb-Downward and Noverr, 2007).

Several incidences of VVC and the emergence of RVVC, after antifungal agent treatments, stimulate the researches to elucidate the mechanisms involved in $C$. albicans pathogenicity and the vaginal immunological response pattern. Thus, the aims of this investigation were to evaluate the patterns involved in cell immunological response (mast cell and neutrophils) as well as to investigate the release of IgE and PGE2 during the murine vaginal candidiasis evolution.

\section{Experimental Procedures}

This research is an experimental study that was performed at Faculdade de Medicina de Ribeirão PretoUSP (FMRP-USP). It was conducted according to ethical principles and started after the project had been approved by the Ethics Committee on Animal Experiments (CETEA) of that institution.

\section{Candida Albicans Sample}

C. albicans strains were isolated from patients with fungemia that were being treated at Hospital das Clínicas da Faculdade de Medicina de Ribeirão Preto, Universidade de São Paulo (FMRP-USP). The isolates were stored in sterile distilled water and stocked at the Fungi Collection of Medical Mycology Laboratory, Department of Cell Biology, Molecular and Pathogenic Bioagents (FMRP-USP). The microorganism identification was performed using standard methods for C. albicans characterization, such as: Germ tube formation in fetal bovine serum at $37^{\circ} \mathrm{C}$, chlamydospores formation on corn meal-agar medium and auxanogram test. In order to perform this research, the strain that demonstrated high virulence aspect was chosen, parameter evaluated by phospholipase and proteinase activity measurement (Lacaz, 2002).

\section{Inoculums Preparation and Experimental Infection}

C. albicans was grown in Sabouraud dextrose agar with $50 \mathrm{mg} \mathrm{L}^{-1}$ chloramphenicol (SDAC) at $35^{\circ} \mathrm{C}$ for 24 h. A fresh colony was then transferred to $5 \mathrm{~mL}$ of liquid medium and incubated at $35^{\circ} \mathrm{C}$ for $48 \mathrm{~h}$ in a shaker, followed by centrifugation at $2000 \mathrm{rpm}$ for $15 \mathrm{~min}$. The pellet was washed three times with sterile saline solution and then, resuspended in $1 \mathrm{~mL}$ of the same solution for counting cells in a Neubauer chamber. The inoculum solution was prepared in a concentration of $1.5 \times 10^{6}$ cells $\mathrm{mL}^{-1}$ and serial dilutions were plated on SDAC to determine the inoculums viability.

Three days before the experimental infection, 186 BALB/c females mice 7-9 weeks old, obtained from FMRP/USP vivarium, were subcutaneously treated with $0.02 \mathrm{mg}$ estradiol valerate, diluted in $0.1 \mathrm{~mL}$ castor oil heated to $37^{\circ} \mathrm{C}$. This treatment causes changes in the thickness and keratinization of the vaginal epithelium, providing a substrate for attachment, growth and formation of a biofilm by the fungus and optimizes the experimental infection conditions (Cassone et al., 2007). Mice were intravaginally inoculated with $C$. albicans $\left(1.5 \times 10^{6}\right.$ cells $/ 20 \mu \mathrm{L}$ in saline solution $)$, using a blunt needle. Experimental control consisted of treated and non-treated groups with estradiol valerate, non-inoculated with the yeast, but with saline solution. Vaginal walls from the animals were submitted to counting of the colony-forming units, determination of local cellular immune response (mast and polymorphonuclear cells) and dosage of IgE/PGE2 in vaginal tissue during the course of vaginal infection by $C$. albicans.

\section{Experimental Groups}

Three experimental groups were evaluated at the following times: 4, 24, 48 and $192 \mathrm{~h}$.

The right lateral vaginal wall was processed using an Ultra Turrax ${ }^{\circledR}$ T18 basic IKA ${ }^{\circledR}$ homogenizer (Cole Parmer-USA) for the first experimental group, aiming to determine the number of viable yeast cell during the infection course. The left lateral vaginal wall was fixed in $10 \%$ formaldehyde for the histopathological studies by the hematoxylin/eosin, Gomori Trichrome (Gomori, 1950) and toluidine blue staining.

The second group was perfused with $25 \mathrm{~mL}$ Phosphate Buffer (PBS) at $4{ }^{\circ} \mathrm{C}$ to remove circulating blood cells from the vaginal mucosa. Vaginal wall was kept in saline solution for mechanical tissue grinding using an Ultra Turrax ${ }^{\circledR}$ T18 basic IKA ${ }^{\circledR}$ homogenizer (Cole ParmerUSA). The obtained suspension was stored at $-70^{\circ} \mathrm{C}$, for subsequent PGE and IgE quantification by ELISA.

The last experimental group had the vaginal tissue collected, immersed and fixed in $2.5 \%$ glutaraldehyde for electron microscopy analysis after the infection process.

\section{Vaginal Mucosal Yeast Quantification}

Vaginal wall from the infected animals was weighed and homogenized into tubes with $1.0 \mathrm{~mL}$ sterile saline solution with penicillin $\left(100 \mathrm{U} \mathrm{mL}^{-1}\right)$ and streptomycin $\left(100 \mathrm{mg} \mathrm{mL}^{-1}\right)$. The harvested homogenate was used to prepare the serial dilutions $(1: 10,1: 100,1: 1000)$, which were plated on ASDC for viable cells determination. Plates were incubated at $35^{\circ} \mathrm{C}$ for $48 \mathrm{~h}$ and ColonyForming Units (CFU) were quantified. Results were expressed as the CFU log average of five animals per infection time studied by the formula:

$$
\begin{aligned}
& \text { Log } 10=[\text { CFU average } \times(\text { dilution } \times 2) \times(X+\text { organ } \\
& \text { weight })] \\
& X=\text { Solution volume used for grinding the organ }
\end{aligned}
$$




\section{Histopathological Analysis of Infected Vaginal Tissue}

Vaginal wall was fixed in $10 \%$ formalin and $10 \mu \mathrm{m}$ thick histological sections were stained with hematoxylin/eosin and Gomori Trichrome (Gomori, 1950) for histopathological studies, during all the course of infection. The analysis was performed in optical microscope Olympus at 100 and $400 \times$ magnification followed by photo documentation.

\section{Scanning Electron Microscopy (SEM)}

Vaginal tissues were collected and immersed in $2.5 \%$ glutaraldehyde, for $3 \mathrm{~h}$ for the fixation. Then the tissue was washed three times with $0.1 \mathrm{M}$ phosphate buffer for $5 \mathrm{~min}$ and post-fixated in phosphate buffered solution with $1 \%$ osmium tetroxide. A new wash was performed with phosphate buffer solution. This material was dehydrated in acetone $30,50,70,90$ and $95 \%$ for $15 \mathrm{~min}$ in each step and then in $100 \%$ acetone, three times for 20 min. In the next step, the material infiltration was performed in resin/acetone (v:v), for $48 \mathrm{~h}$ under stirring. The material was transferred to pure resin (Araldite 6005), for $2 \mathrm{~h}$ at $45^{\circ} \mathrm{C}$, immersed in silicone containers properly oriented and followed by the resin polymerization for $72 \mathrm{~h}$ at $60^{\circ} \mathrm{C}$. Samples were processed on Bal-Tec CPD 030 equipment to obtain the critical point. Vaginal tissue assembly was done in special supports that allow the electron conduction. The last step was the gold rinsing in the Bal-Tec SCD 050 equipment. Analysis of all samples was performed in a scanning electron microscope (JEOL JSM 5200 scanning microscope).

\section{Mast Cells Detection using Toluidine Blue}

Vaginal tissue was de-waxed in xylol1 and xylol2 for 3 min. Then, the sections were hydrated in: Alcoholxylene, absolute alcohol and alcohol 95, 90, 80, 70 and $50 \%$, for $2 \mathrm{~min}$ and washed with water. The slides were stained with $0.1 \%$ toluidine blue at $\mathrm{pH} 2.8$ for $20 \mathrm{~min}$ and dehydrated in 90\% ethanol, 95 and 100\%, absolute ethanol-xylol, xylol1 and xylol 2 for $3 \mathrm{~min}$. Analyses were performed in optical microscope.

\section{Prostaglandin E2 Detection and Quantification}

Homogenized tissues stored in $0.85 \%$ saline solution at $-70^{\circ} \mathrm{C}$ were treated with $1 \mathrm{~N} \mathrm{HCl}$ and centrifuged at $2000 \mathrm{rpm}$ up to the solubilization. Then, these materials were purified on columns (Sep-Pak ${ }^{\circledR}$ Cartridges) to separate the lipid components and aliquots of $50 \mu \mathrm{L}$ of each treated sample were transferred into 96-well plates (Prostaglandin $\mathrm{E}_{2}$ direct Biotrak Assay Kit-GE Healthcare Life Science), which already had the primary antibody (anti-goat IgG mouse). Each well was covered with $50 \mu \mathrm{L}$ of secondary anti-PGE2 and $50 \mu \mathrm{L}$ of the secondary antibody conjugated to peroxidase. The plate was incubated for $1 \mathrm{~h}$ under stirring in light privation.
After this procedure, the plates were washed with washing buffer from the kit and $150 \mu \mathrm{L}$ well ${ }^{-1}$ of development solution was added, followed by the incubation for $30 \mathrm{~min}$. The reaction was stopped by adding $100 \mu \mathrm{L}$ well $^{-1}$ of $1 \mathrm{M}$ sulfuric acid and the results were obtained in an ELISA reader at $450 \mathrm{~nm}$. Sample quantifications were evaluated according to the standard curve from the Kit. The results were expressed as the average measurements obtained in two experiments, five animals for each infection time.

\section{Detection of $\operatorname{IgE}$}

IgE detection was performed with ELISA assay using $100 \mu \mathrm{L}$ of homogenized samples stored in $0.85 \%$ saline without dilution and transferred to 96-well plates (Corning Costar ${ }^{\circledR}$ Incorporated). Each well was covered with $100 \mu \mathrm{L}$ IgE capture primary antibody (BD Biosciences) $\left(2 \mathrm{mg} \mathrm{mL}^{-1}\right)$ and the plate was incubated overnight at $4^{\circ} \mathrm{C}$. The next step was nonspecific sites blocking using $200 \mu \mathrm{L}$ PBS with $1 \%$ BSA for $1 \mathrm{~h}$, follow by washing with PBS containing $0.05 \%$ Tween 20. All samples were incubated with the biotinylated anti-mouse IgE secondary antibody (BD Biosciences) (4 $\mathrm{mg} \mathrm{mL}{ }^{-1}$ ) for $1 \mathrm{~h}$ and washed one more time.

Finally, it was added $100 \mu \mathrm{L}$ well ${ }^{-1}$ of avid inhorseradish peroxidase complex (BD Biosciences) diluted in blocking buffer $(1: 1000)$ for $30 \mathrm{~min}$ in light privacy. The reaction was developed with $100 \mu \mathrm{L}$ well ${ }^{-1}$ Tetramethylbenzidine (TMB) for $10 \mathrm{~min}$ and stopped by adding $100 \mu \mathrm{L}$ of sulfuric acid $1 \mathrm{M}$ per well. Results were obtained on ELISA reader at $450 \mathrm{~nm}$.

\section{Statistical Analysis}

The normal distribution of the studied samples was performed by the Shapiro-Wilk test and for the comparison among them the one-way analysis of variance was applied. Graph Pad Prism ${ }^{\circledR} 3.0$ (CA, EUA) software was used. The statistical significance was accepted at $\mathrm{p}<0.05$.

\section{Results}

The efficiency of the murine infection by C. albicans was demonstrated by some parameters. The UFC counting demonstrated that all evaluated groups presented increasing levels of infection according to the infection evolution (data not shown). After $24 \mathrm{~h}$, there was the prevalence of parasitism under the pseudohyphae form, with growth of infectious cells in the epithelial layer without invasion in deep layers. These results were confirmed by hematoxylin and eosin staining, specific fungi staining, the Gomori Trichrome (Gomori, 1950) and also, by scanning electronic microscopy (Fig. 1).

Figure 2 shows the typical presence of a polymorphonuclear cells (PMN) microabscess in the mucosal layer. 


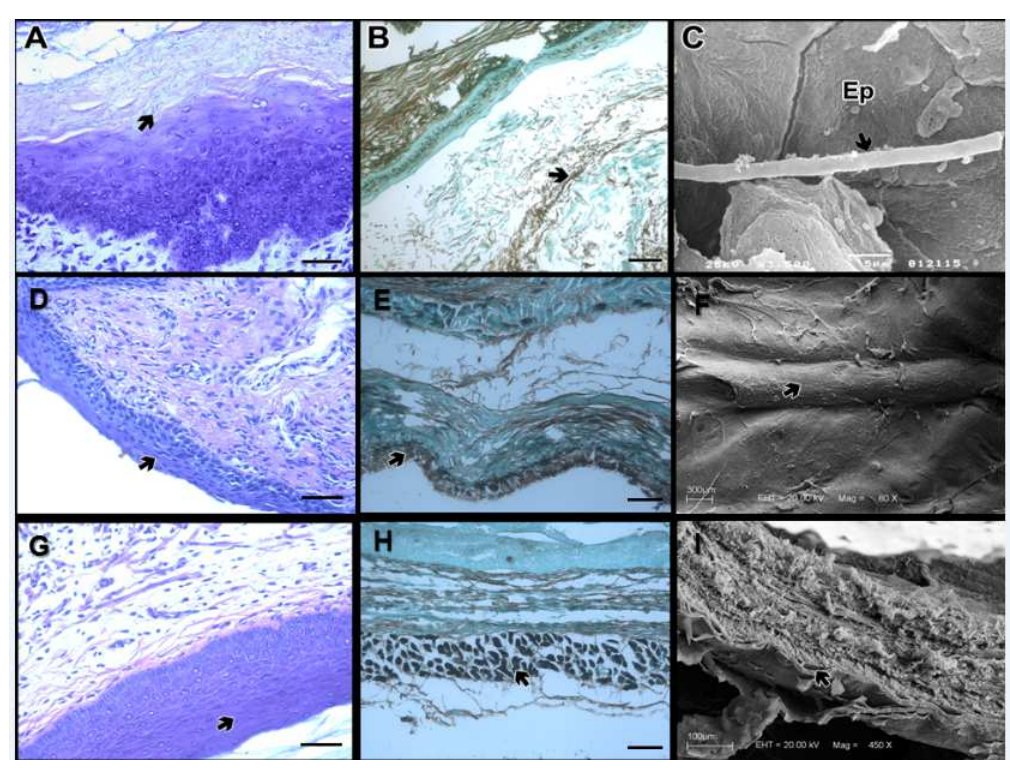

Fig. 1. Surface parasitism of mice vaginal mucosa after $48 \mathrm{~h}$ post-infection by C. albicans. Hematoxylin-eosin (A) and Gomori Methanamine/Silver (GMS). Barr: $50 \mu \mathrm{m}$. (B) showing numerous pseudohyphae nonadherent. Barr: $250 \mu \mathrm{m}$. Scanning electron microscopy (C), showing the stratified Epithelium (Ep) and pseudohyphae free (Arrow), 3500× magnification

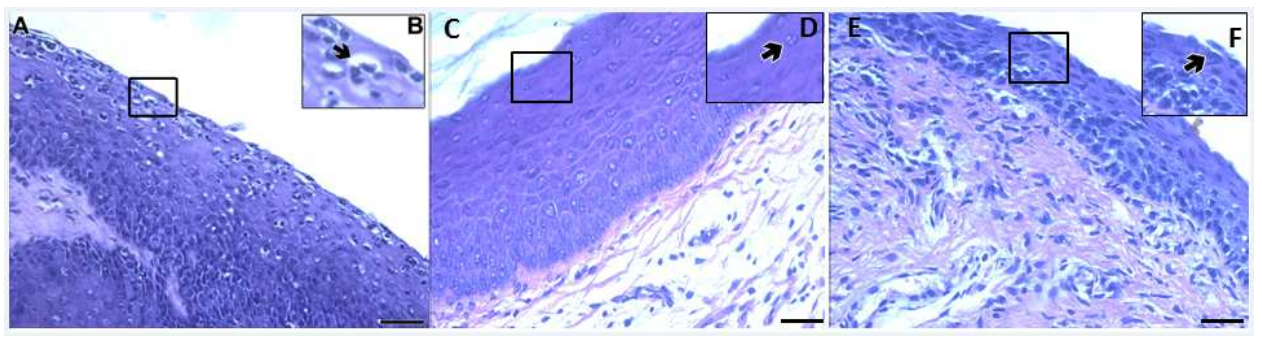

Fig. 2. Polymorphonuclear microabscess cells in mice mucosal surface infected with Candida albicans after $120 \mathrm{~h} \mathrm{~A}$ and B; C and $\mathrm{D}=$ uninfected controls untreated and $\mathrm{E}$ and $\mathrm{F}=$ controls treated with $0.02 \mathrm{mg}$ of estrogen, respectively showing absence of polymorphonuclear microabscess (Arrow). Barr: $50 \mu \mathrm{m}$

Mast cells could be visualized in all infection times, evidenced by wine staining due to the metachromasia phenomenon, with an increase of these cells at further infection times, which corresponded to the infection response (Fig. 3).

In the first infection times, PGE2 dosages were observed in quite elevated levels compared to the noninfected controls. After $48 \mathrm{~h}$, there was a PGE2 pick and a new exacerbation in $192 \mathrm{~h}$, which corresponded, to yeasts increase and pseudohyphae presence, in the histopathological sections (Fig. 4).

$\mathrm{IgE}$ dosage elevation in the vaginal tissue was observed after $48 \mathrm{~h}$ of infection remained elevated in the subsequent time, which was coincident with mast cell degranulation detection in the vaginal mucous membrane (Fig. 5).

\section{Discussion}

The pleomorphic $C$. albicans yeast lives in association with humans, resulting in a positive commensalism interaction. This fungus is a member of the normal human microbiota and colonizes the mucosal surface of gastrointestinal tract, vagina and the surface of humid skin (Yang, 2003; Fischer, 2012).

According to (Chaffin et al., 1998), this delicate balance can be broken and start a parasitic relationship, resulting in an infection called candidiasis. Among the most important $C$. albicans virulence factors are the secretion of hydrolytic enzymes, morphological transition mechanisms (pleomorphism), antigenic variability and the immunomodulation of host defense mechanisms (Sturtevant and Calderone, 1997).

Currently, rats and mice are considered the most used animal as models to study candidiasis (Carrara et al., 2010; Yano and Fidel, 2011). Fidel et al. (1993) established the following steps are necessary to the persistent vaginal infection development, which constitutes fungus penetration, tissue invasion, development and proliferation of this fungus in these animals and the estrogen treatment to induce a pseudo-estrus state. 


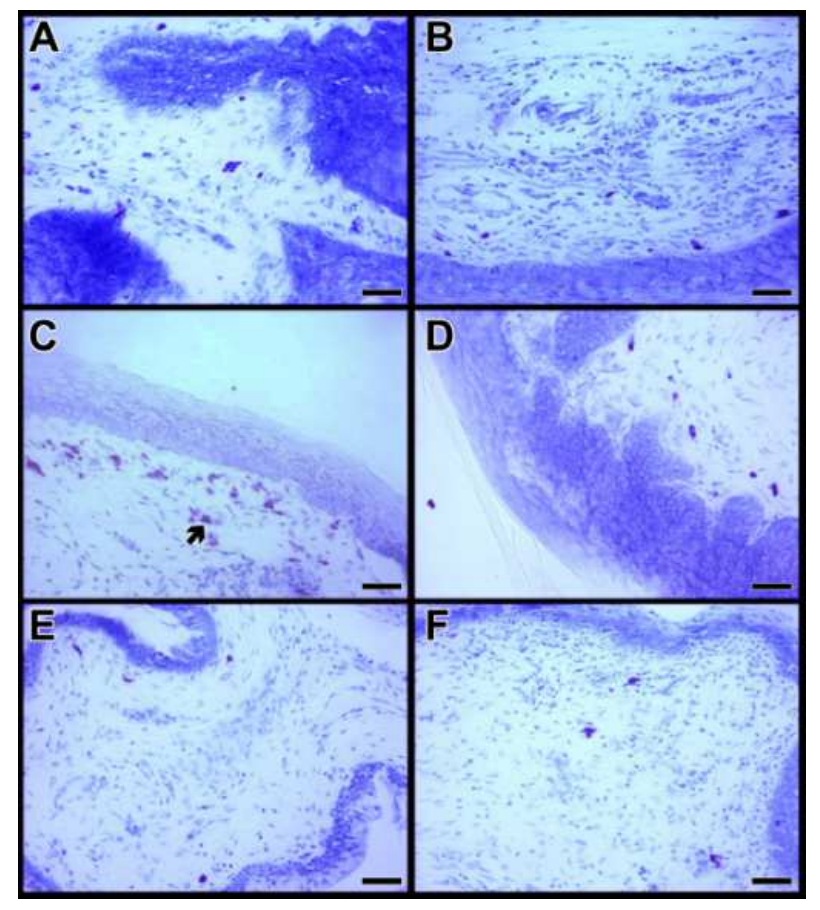

Fig. 3. Paraffin sections of mice vaginal tissue stained with toluidine blue, indicating mast degranulated: A, B, C and $\mathrm{D}=4,24,48$ and $192 \mathrm{~h}$ post-infection, respectively. $\mathrm{E}$ and $\mathrm{F}=$ uninfected controls, untreated and, treated with $0.02 \mathrm{mg}$ of estrogen, respectively. Barr: $50 \mathrm{um}$

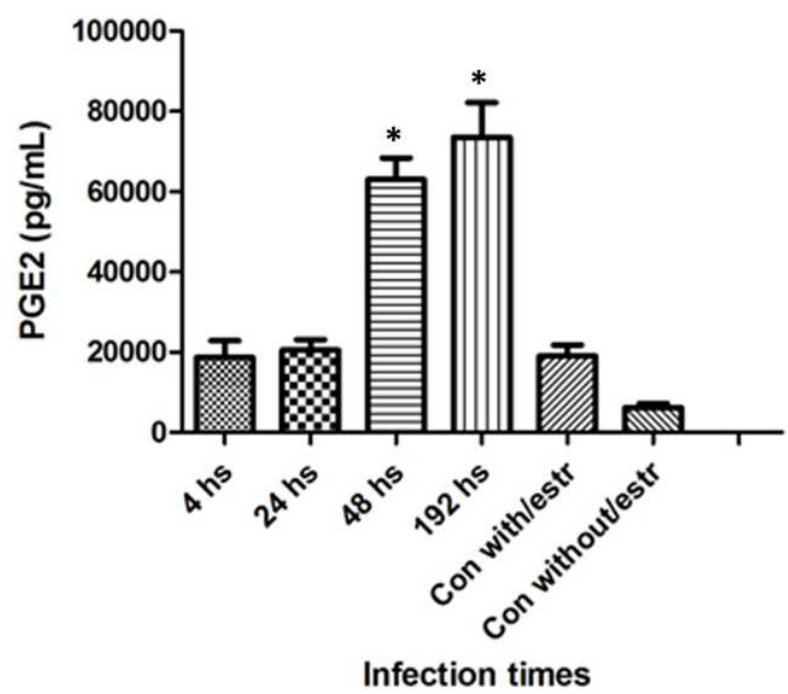

Fig. 4. PGE2 (pg/mL) detection in vaginal tissue of mice infected with C. albicans. Results represent the average of two measurement experiments using 5 animals for each infection time. One-way ANOVA, ${ }^{*} \mathrm{p}<0.001$

This differentiated hormonal system promotes the vaginal epithelium stratification and the keratin layer development that covers this epithelium, what is essential for the $C$. albicans attachment (Carrara et al., 2010).

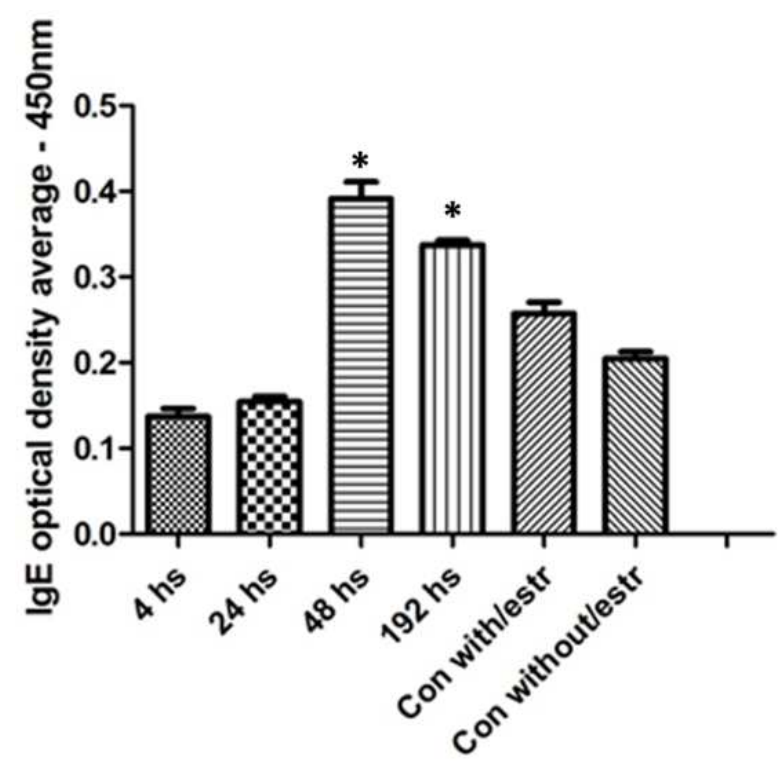

Infection times

Fig. 5. IgE detection in vaginal tissue of mice infected with C. albicans. Results represent the optical density average of two measurement experiments using 5 animals for each infection time. One-way ANOVA, ${ }^{*} \mathrm{p}<0.001$

Another characteristic that shows the yeast invasive ability and the persistent infection establishment is the pleomorphism (Davies et al., 1999). Many genes are associated to this feature and, in most cases, depend on the chemical and physical environmental conditions where the fungus is growing. Studies with $C$. albicans strains that had mutations in genes involved in the transition form, showed a reduction in virulence power, which had lost this characteristic (Calderone and Fonzi, 2001; Romani et al., 2003).

According to the results shown in Fig. 1, the infected animals showed the hyphae and pseudo-hyphae morphology predominance, which supported the hypothesis that $C$. albicans invasion and fixation in the vaginal tissue depended on this morphological transition.

Micro-abscesses consisting mainly of polymorphonuclear cells were checked by hematoxylineosin staining in the mucosal layer (Fig. 2) prior to the infection time, however in some infection times detectable changes in the cellular pattern of the sub mucosal layer were observed, possibly due to lack of fungi invasion in deeper structures, which could lead to more effective and diversified cellular immune response (Black et al., 1998; de Bernardis et al., 2000). Yano et al. (2012) demonstrated an important polymorphonuclear role in the symptomatic VVC infection establishment, which seems to be related to alarmins production by the vaginal epithelial cells. These molecules are able to attract PMN and contribute to the acute VVC symptoms. However, the exactly immunological mechanism 
involved in this response remains unclear. Other study showed that the PMN action on the vaginal tissue is responsible for the high infection levels, which provides tissue damage in VVC patients (Beghini et al., 2012).

One proposed hypothesis to explain the vaginal candidiasis pathogenesis is the allergic response. $C$. albicans is able to induce the production of different antibodies classes, such as $\operatorname{IgG}$, IgA and IgE. Some studies have demonstrated the IgE presence in serum and vaginal secretions in $87 \%$ of women with vaginal candidiasis (Witikin et al., 1988; Regúlez et al., 1994) increasing the premise that the immunoglobulin role in the vaginal candidiasis pathogenesis is associated to the histamine released by locally mast cells. Furthermore, histamine is able to locally induce the prostaglandin E2 production that may be responsible for the local immune response and immunomodulation process (Witikin et al., 1988; Noverr et al., 2001; Regúlez et al., 1994).

Thus, PGE2 and IgE (Fig. 4 and 5) detection results showed an increase in the concentration of these mediators prior to infection times, which were more significant for PGE2, since its concentration was determined using a standard curve. No standard IgE curve was constructed and the results showed only a difference in absorbance between samples at $450 \mathrm{~nm}$, which indirectly represents the difference in their concentrations. Analysis of tissues stained with toluidine blue showed increased mast cell previous to infection times (Fig. 3), which coincide with the IgE and PGE2 increase. These findings may explain the mechanisms involved in the vaginal tissue immune response and immune response associated to an allergic pattern.

It is recognized that symptomatic patients with frequent recurrences have higher IgE anti-Candida levels in vaginal contents than in normal or asymptomatic patients. The number of mast cells present in normal vaginal mucosa is small; however, it seems to be increased during the infection caused by some genera such as Candida, Chlamydia and Trichomonas (Witikin et al., 1988).

Studies have shown that the increase in PGE2 during C. albicans infections may be associated with the fungus colonization, because it facilitates the yeast morphological transition to pseudohyphae, follow by Th1-type immune response inhibition, chemokine release, phagocytosis and lymphocyte proliferation, culminating in Th2 type immune response and tissue eosinophilia (Noverr et al., 2001; 2002; Erb-Downward and Noverr, 2007; Kalo-Klein and Witkin, 1990).

According to (Barousse et al., 2005) there is an important anti-Candida activity in epithelial cells, raising the hypothesis that the VVC susceptibility is associated to signs from vaginal epithelial cell interaction with Candida, which promotes clinical symptoms such as leukocyte inflammatory response, but no protective, while VVC resistance is associated to the lack of signs and/or antifungal epithelial cells activity and absence of inflammation (Fidel, 2007; Jaeger et al., 2013).

Treatment against $C$. albicans consists in use, in the most of time, "azoles", especially fluconazole to control the pathogen proliferation. In this case, these treatments don't affect directly the PMNs or mast cell migration and mediator secretion, but these drugs interfere on the development, affecting the biosynthesis of ergosterol. Thus, with the decrease of pathogen number, the local immune response decreases too, restoring the balance of the vaginal flora (Cassone, 2015).

However, in the few years there has been reported an increase of pathogen resistance to the antifungal treatment, some explanations by this increase is related especially to some genetics aspects of this yeast, such as modifications in its sterol biosynthesis pathway by the mutations or over expression of genes involved in this event, alteration of genes encoding efflux pumps of the drugs and also its transporters. Thus, due to these mechanisms already explained the pathogen population is always high, maintaining the local immune response high too, which explains the most of results obtained in this research (Sobel, 2016; Akins, 2005; Morschhäuser, 2002).

\section{Conclusion}

VVC is a public health problem with high occurrence rates that should be carefully monitored by the scientific community, in addition to the conventional therapies for the prevention of VVC which become obsolete, each year and do not prevent recurrence.

Thus, this research tried to elucidate some aspects of vaginal tissue physiology and immunological mechanisms involved in the VVC, opening new perspectives to future studies about cell signaling and host-parasite interaction in infectious processes, providing scientific basis for more effective prophylactic and therapeutic interventions against vaginal yeast infections.

\section{Acknowledgement}

We are thankful for the technical support from Marly de Castro, Deise Lúcia Chesca, Carlos Sorgi, Maria Dolores, Vani Alves and Auristela.

\section{Funding Information}

There was no specific financial support for this research.

\section{Author Contributions}

Rosymar Coutinho Lucas and Carol K. Da Fonseca: Design and development of the study. Rodrigo A. Cazzaniga and Carolina Nunes França: Analysis of the results. 
Fernando Segato, Rafael Taglialegna and Claudia M.L. Maffei: Development of the manuscript.

\section{Conflict of Interest}

The authors report no conflicts of interest. The authors alone are responsible for the content and the writing of the paper.

\section{References}

Akins, R.A., 2005. An update on antifungal targets and mechanisms of resistance in Candidaalbicans. Med. Mycol., 43: 285-318. DOI: $10.1080 / 13693780500138971$

Barousse, M.M., T. Espinosa, K. Dunlap and P.L.Jr. Fidel, 2005. Vaginal epithelial cell anti-Candida albicans activity is associated with protection against symptomatic vaginal candidiasis. Infect. Immun., 73: 7765-7767. DOI: $10.1128 /$ IAI.73.11.7765-7767.2005

Beghini, J., P.C. Giraldo, R. Riboldi, R.L. Amaral and J. Jr. Eleutério et al., 2012. Altered CD16 expression on vaginal neutrophils from women with vaginitis. Eur. J. Obstet. Gynecol. Reprod. Bio., 167: 96-99. DOI: 10.1016/j.ejogrb.2012.11.008

Bennett, R.J. and A.D. Johnson, 2005. Mating in Candida albicans and the search for a sexual cycle. Annu. Rev. Microbiol., 59: 233-255.

DOI: 10.1146/annurev.micro.59.030804.121310

Black, C.A., F.M. Eyers, A. Russell, M.L. Dunkley and R.L. Clancy et al., 1998. Acute neutropenia decreases inflammation associated with murine vaginal candidiasis but has no effect on the course of infection. Infect. Immun., 66: 1273-1275.

Calderone, R.A. and W.A. Fonzi, 2001. Virulence factors of Candida albicans. Trends Microbiol., 9: 327-335. DOI: 10.1016/S0966-842X(01)02094-7

Carrara, M.A., L. Donaltti, E. Damke, T.I. Svidizinski and M.E. Consolaro et al., 2010. A new model of vaginal infection by Candida albicans in rats. Mycopathologia, 170: 331-338.

DOI: $10.1007 / \mathrm{s} 11046-010-9326-1$

Cassone, A., 2015. Vulvovaginal Candida albicans infections: Pathogenesis, immunity and vaccine prospects, BJOG, 122: 785-94. DOI: $10.1111 / 1471-0528.12994$

Cassone, A., F. De Bernardis and G. Santoni, 2007. Anticandidal immunity and vaginitis: Novel opportunities for immune intervention. Infect. Immun., 75: 4675-4686. DOI: 10.1128/IAI.00083-07

Chaffin, W.L., J.L. López-Ribot, M. Casanova, D. Gozalbo and J.P. Martinez, 1998. Cell wall and secreted proteins of Candida albicans: Identification, function and expression. Microbiol. Mol. Biol. Rev., 62: 130-180. PMID: 9529890
Davies, J.M., A.J. Stacey and C.A. Gilligan, 1999. Candida albicans hyphal invasion: Thigmotropism or chemotropism?. FEMS Microbiol. Lett., 171: 245-249. DOI: 10.1111/j.1574-6968.1999.tb13439.x

de Bernardis, F., G. Santoni, M. Boccanera, E. Spreghini and D. Adriani et al., 2000. Local anticandidal immune responses in a rat model of vaginal infection by and protection against Candida albicans. Infect. Immun., 68: 3297-3304. DOI: 10.1128/IAI.68.6.3297-3304.2000

Erb-Downward, J.R. and M.C. Noverr, 2007. Characterization of prostaglandin E2 production by Candida albicans. Infect. Immun., 75: 3498-3505.

Fidel, P.L. Jr., 2007. History and update on host defense against vaginal candidiasis. Am. J. Reprod. Immunol., 57: 2-12. DOI: $10.1111 / \mathrm{j} .1600-0897.2006 .00450$

Fidel, P.L. Jr., J.L. Cutright and J.D. Sobel, 1995. Effects of systemic cell-mediated immunity on vaginal candidiasis in mice resistant and susceptible to Candida albicans infections. Infect. Immun., 63: 4191-4194.

Fidel, P.L. Jr., M.E. Lynch and J.D. Sobel, 1993. Candidaspecific cell-mediated immunity is demonstrable in mice with experimental vaginal candidiasis. Infect. Immun., 61: 1990-1995. PMID: 8097493

Fischer, G., 2012. Chronic vulvovaginal candidiasis: What we know and what we have yet to learn. Aus. J. Dermatol., 53: 247-254. DOI: $10.1111 / \mathrm{j} .1440-0960.2011 .00860 . \mathrm{x}$

Gomori, G., 1950. A rapid one-step trichrome stain. Am. J. Clin. Path., 20: 661-664. PMID: 15432364

Harriott, M.M., E.A. Lilly, T.E. Rodriguez, P.L. Jr. Fidel and M.C. Noverr, 2010. Candida albicans forms biofilms on the vaginal mucosa. Microbiology, 156: 3635-3644. DOI: 10.1099/mic.0.039354-0

Jaeger, M., T.S. Plantinga, L.A. Joosten, B.J. Kullberg and M.G. Netea, 2013. Genetic basis for recurrent vulvo-vaginal candidiasis. Curr. Infect. Dis. Rep., 15: 136-142. DOI: 10.1007/s11908-013-0319-3

Kalo-Klein, A. and S.S. Witkin, 1990. Prostaglandin E2 enhances and gamma interferon inhibits germ tube formation in Candida albicans. Infect. Immun., 58: 260-262. PMID: 2152888

Lacaz, C.S., 2002. Tratado de Micologia Médica. 9th Edn., Sarvier, São Paulo, ISBN-10: 8573781238, pp: 1104.

McCullough, M.J., B.C. Ross and P.C. Reade, 1996. Candida albicans: A review of its history, taxonomy, epidemiology, virulence attributes and methods of strain differentiation. Int. J. Oral Maxillofac. Surg., 25: 136-144. DOI: 10.1016/S0901-5027(96)80060-9

Morschhäuser, J., 2002. The genetic basis of fluconazole resistance development in Candida albicans. Biochim. Biophys. Acta., 18: 240-248. PMID: 12084466 
Noverr, M.C., G.B. Toews and G.B. Huffnagle, 2002. Production of prostaglandins and leukotrienes by pathogenic fungi. Infect. Immun., 70: 400-402. DOI: 10.1128/IAI.70.1.400-402.2002

Noverr, M.C., S.M. Phare, G.B. Toews, M.J. Coffey and G.B. Huffnagle, 2001. Pathogenic yeasts Cryptococcus neoformans and Candida albicans produce immunomodulatory prostaglandins. Infect. Immun., 69: 2957-2963. DOI: 10.1128/IAI.69.5.2957-2963.2001

Regúlez, P., J.F. García Fernández, M.D. Moragues, J. Schneider and G. Quindós et al., 1994. Detection of anti-Candida albicans IgE antibodies in vaginal washes from patients with acute vulvovaginal candidiasis. Gynecol. Obstet. Invest., 37: 110-114. DOI: $10.1159 / 000292536$

Romani, L., F. Bistoni and P. Puccetti, 2003. Adaptation of Candida albicans to the host environment: The role of morphogenesis in virulence and survival in mammalian hosts. Curr. Opin. Microbiol., 6: 338-343. DOI: $10.1016 / \mathrm{S} 1369-5274(03) 00081-\mathrm{X}$

Sobel, J.D., 2016. Recurrent vulvovaginal candidiasis. Am. J. Obstet. Gynecol., 214: 15-21.

DOI: $10.1016 /$ j.ajog.2015.06.067
Sturtevant, J. and R. Calderone, 1997. Candida albicans adhesins: Biochemical aspects and virulence. Rev. Iberoam. Micol., 14: 90-97. PMID: 17655381

Witikin, S.S., J. Jeremias and W.J. Ledger, 1988. A localized vaginal allergic response in women with recurrent vaginitis, J. Allergy Clin. Immunol., 81: 412-416. DOI: 10.1016/0091-6749(88)90909-8

Yang, Y.L., 2003. Virulence factors of Candida species. J. Microbiol. Immunol. Infect., 36: 223-228. PMID: 14723249

Yano, J. and P.L. Jr. Fidel, 2011. Protocols for vaginal inoculation and sample collection in the experimental mouse model of Candida vaginitis. J. Vis. Exp., 8: 3382-3382. PMID: 22215135

Yano, J., J.K. Kolls, K.I. Happel, F. Wormley and K.L. Wozniak et al., 2012. The acute neutrophil response mediated by $\mathrm{S} 100$ alarmins during vaginal Candida infections is independent of the Th17pathway. PLoS One, 7: 1-8. DOI: 10.1371/journal.pone.0046311 